Biosystems Engineering (2007) 96(4), 565-580

doi:10.1016/j.biosystemseng.2007.01.007

SE-Structures and Environment
Available online at www.sciencedirect.com

ScienceDirect

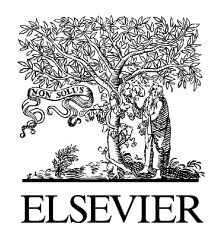

\title{
Frictional Interactions between Bovine Claw and Concrete Floor
}

\author{
A. Franck ${ }^{1}$; G. Opsomer ${ }^{2}$; A. de Kruif ${ }^{2}$; N. De Belie ${ }^{1}$ \\ ${ }^{1}$ Magnel Laboratory for Concrete Research, Department of Structural Engineering, Faculty of Engineering, Ghent University, \\ Technologiepark-Zwijnaarde 904, B-9052 Gent, Belgium; e-mail of corresponding author: nele.debelie@ugent.be \\ ${ }^{2}$ Department of Reproduction, Obstetrics, and Herd Health, Faculty of Veterinary Medicine, Ghent University, Salisburylaan 133 , B-9820 \\ Merelbeke, Belgium; e-mail: geert.opsomer@ugent.be
}

(Received 8 March 2006; accepted in revised form 22 January 2007; published online 9 March 2007)

Inadequate properties of concrete floors in cattle houses are a major cause of claw problems, resulting in economic losses and impaired animal welfare. Many claw diseases are sequels of an extreme local overload due to high floor roughness or are caused by the indirect effects of the slipperiness of the floor. In this paper, the roughness of the concrete floor, the frictional interactions between bovine claw and floor and the relation between roughness and frictional properties, are studied.

Concrete floor samples were made with five different finishing methods. Their roughness was determined by measuring the heights of the 'peaks and valleys' of the surface with a high-precision laser beam. The smoothest surface was the sample finished with a metal float (average surface roughness $R_{a}=0.080 \mathrm{~mm}$ ) and the roughest surface occurred with the heavily sandblasted sample (average surface roughness $R_{a}=0.296 \mathrm{~mm}$ ). Their roughness was also approximated with the 'sand-patch' method: the texture depth was calculated by dividing a fixed volume of fine dry sand by the surface area of the circle-shaped sand patch. Again the smoothest surface appeared to be the sample finished with a metal float (texture depth $=0.19 \mathrm{~mm}$ ) and the roughest surface was the heavily sandblasted sample (texture depth $=0.59 \mathrm{~mm}$ ). The sand-patch method appeared to be a reliable way of assessing the roughness of the floor.

The static coefficient of friction $\mu_{\text {stat }}$ and the dynamic coefficient of friction $\mu_{d y n}$ between bovine claw models and dry and wet floors were determined by using the 'drag method' (a loaded bovine claw was dragged using a hand-operated winch over a flat floor sample while the tensional force was recorded). The five concrete floor panels with different roughnesses were used, but also two types of synthetic floor coverings (mat and mattress) were added to the test. The static coefficient of friction on dry floors varied between 0.60 (mattress) and 0.79 (mildly sandblasted concrete); the dynamic coefficient of friction ranged between 0.47 (mattress) and 0.69 (heavily sandblasted concrete). In wet circumstances only three floor types were tested. The static coefficient of friction varied between 0.65 (metal-floated concrete) and 0.80 (heavily sandblasted concrete) while the dynamic coefficient of friction yielded values between 0.56 (metal-floated concrete) and 0.69 (heavily sandblasted concrete). Significant differences were found between the floor types, but these were mainly due to the values measured on the metal-floated concrete, the mattress and the mat. Only in dry circumstances did the fore claws produce significantly higher coefficients of friction than the hind claws. The effect of the floor type on the coefficients of friction was in all cases many times higher than the effect of the claw itself. The static and the dynamic coefficients of friction in wet conditions were found to be larger than the same coefficients in dry conditions.

The skid or slip resistance was measured separately, on wetted surfaces, with the skid-resistance tester (SRT) pendulum. The values found ranged between $20 \cdot 2$ (metal-floated concrete) and $49 \cdot 6$ (mattress). Significant differences between the floor types were found.

Significant correlations were found between the static and the dynamic coefficients of friction, in dry and wet conditions, and the roughness values $R_{x}$ and the texture depth. Significant correlations were also found between the SRT values and the roughness values $R_{x}$. Significant correlations were found only between the dynamic coefficients of friction and SRT values. 


\begin{tabular}{|llll|}
\hline & & Notation & \\
$D_{\text {max }}$ & maximum diameter, $\mathrm{mm}$ & & \\
$E$ & Young's modulus, $\mathrm{MPa}$ & $R_{x}$ & generic roughness value, $\mathrm{mm}$ \\
$F_{N}$ & normal force, $\mathrm{N}$ & $R_{z}$ & peak-to-valley height, $\mathrm{mm}$ \\
$F_{T}$ & horizontal tensile force, $\mathrm{N}$ & $\alpha$ & significance threshold \\
$N$ & number of samples & $\mu$ & coefficient of friction \\
$P$ & probability & $\mu_{d y n}$ & dynamic coefficient of friction \\
$R_{a}$ & centre-line roughness value, mm & $\mu_{s t a t}$ static coefficient of friction \\
$R_{q}$ & root-mean-square roughness value, $\mathrm{mm}$ & $\rho$ & Pearson correlation \\
& & \\
\hline
\end{tabular}

The measured coefficients of friction were all higher than the required coefficients of friction, hence the tested floor samples provided enough resistance against slip.

(C) 2007 IAgrE. All rights reserved

Published by Elsevier Ltd

\section{Introduction}

Lameness in cattle is widely recognised as a major economic and welfare problem (Vermunt \& Greenough, 1996; De Kruif \& Opsomer, 2005). A wide range in the prevalence of lameness in dairy cattle is encountered. The dairy cow's environment (amongst others, the type of flooring surface) may be the main determinant of the degree of lameness (Cook et al., 2004). Lowering the prevalence of claw disorders and lameness incidents in current housing systems requires more insight into the floor factors that are involved (Somers et al., 2003).

In modern farms cattle are almost uniquely housed on full concrete floors or on pre-fabricated slatted concrete floors because of the durability and cost-effectiveness. Despite these advantages, $80 \%$ of the cows exposed to concrete flooring are affected by one or more claw disorders at the same time. Cows housed in straw yard systems have the lowest levels of claw disorders, a marked contrast to concrete flooring (Somers et al., 2003). Somers et al. (2005) confirmed that cows in straw yards had smaller lesion scores for digital dermatitis than cows housed on solid or grooved concrete floors.

Animals often show claw diseases which are considered to be the direct and indirect effect of the roughness and slipperiness of the floor (McDaniel \& Wilk, 1991). It is believed that the processes of normal horn production and abrasion are disturbed by abnormal load bearing on a hard floor. This results in claw malformation (van der Tol et al., 2002). Increased growth rate of the horn can occur with (free stall) housed cattle (Vermunt, 1996) and the wear rate often exceeds the rate of claw horn growth (Shearer \& van Amstel, 2003).

The largest problem concerning the floor friction in livestock buildings is that the surface must not be so slippery that the animals have to make special exertions.
Neither must it be so rough that abrasions or wounds arise. The friction a surface poses in a certain situation depends to a large extent not only on its general friction properties but also on how the animal applies the slipping load (e.g. contact surface, contact angle, speed, etc.) and whether the surface is dry, wet or dirty (Nilsson, 1988). Floor friction has a considerable impact on the walking pattern of cows (Phillips \& Morris, 2001).

Surface roughness assists cattle movement by improving frictional properties and reducing slipperiness; conversely the wear rate of claw horn is increased which leads to a less protruding wall, thin sole, and thus lameness (Bonser et al., 2003).

A better understanding of the consequences of using concrete floors and the causal relation and interaction with claw problems, is necessary to improve floor designs and consequently animal welfare. To optimise animal welfare the floor requires to be sufficiently abrasive to prevent slipping whilst the rates of abrasive wear should not exceed and preferably equal rates of growth (Bonser et al., 2003).

The main factor in relation to slipperiness is the coefficient of friction. The coefficient of friction determines the horizontal (frictional or tensional) force that can be generated between the contact surfaces of two objects per unit of vertical (normal) force between these objects. In cattle locomotion, the coefficient of friction depends on the properties of the claw horn, the concrete floor, and the contact interface. Intervening fluids affect its value. A slipping incident occurs when the required coefficient of friction exceeds the coefficient of friction at the claw-floor interface (van der Tol et al., 2005).

In the current paper, the determination of the roughness of concrete floors and the influence of floor roughness on frictional properties and slip-resistance is 
presented. Also the frictional properties and the skidresistance of two types of synthetic flooring surfaces were tested in this study.

Nilsson (1988) already stated that friction generally decreases with decreasing texturing. It was expected that more rough concrete floors would indeed result in higher friction. This theory was tested by dragging loaded bovine claw models over concrete and synthetic floor samples with different roughness and by measuring the occurring drag force in the meantime. The friction test was performed in both dry and wet conditions.

\section{Materials and methods}

\subsection{Concrete panels and synthetic floor coverings}

Five samples of concrete floors $(1000 \mathrm{~mm}$ length by $300 \mathrm{~mm}$ width by $50 \mathrm{~mm}$ height) were made with five different kinds of surface structure, obtained by varying the finishing method: surfaced with a metal ('Metal') or wooden ('Wood') float, brushed ('Brush') and mildly ('Sand 1') or heavily ('Sand 2') sandblasted. The latter two were included to simulate a degraded concrete floor with protruding coarse (limestone) aggregates (of maximum diameter $D_{\max }=14 \mathrm{~mm}$ ).

Additionally, two types of synthetic floor coverings were tested: a mattress and a mat. Both floor types are further referred to in this manuscript as 'Mattress N' and 'Mat P', respectively. The mattress and the mat were attached to a concrete panel $(1000 \mathrm{~mm}$ length by $300 \mathrm{~mm}$ width by $50 \mathrm{~mm}$ height) according to the guidelines of the manufacturer. The mattress consisted of a layer of thick $(40 \mathrm{~mm})$ latex with a layer of woven polypropylene fibres on top. The fibres were made impermeable for water with a coating just below the fibres. The mat consisted of one layer of pure rubber (thickness: $30 \mathrm{~mm}$ ). The Young's modulus $E$ was determined at $39 \mathrm{MPa}$ for the mattress and at $641 \mathrm{MPa}$ for the mat.

\subsection{Bovine claw preparation}

Sixteen limbs of freshly slaughtered cows were taken from the abattoir. Twelve limbs were from beef cows from the Belgian Blue Beef (BBB) breed which had been housed on slatted floors. Four limbs were from dairy cows (Holstein). All limbs were right limbs: 10 fore and six hind limbs. The claws all had well formed healthy and intact horn walls and soles (without damage or disorders). All limbs had undergone the same treatment: they were cut off the just slaughtered animal, they were cleaned (i.e. the slurry was scraped off and they were washed) and they were immediately put in plastic bags in order to keep their moisture level. Then the limbs were frozen until further preparation. In the frozen state, the claws were sawn off just above the horn wall, with the saw cut parallel to the sole just before they were tested. The claw was then defrosted in order to enable the two toes to be manipulated (they had to be positioned at the same level). The claw was put in a polyvinyl chloride (PVC) tube (inner diameter $150 \mathrm{~mm}$ and height $120 \mathrm{~mm}$ ) with the sole of the claw making contact with a horizontal surface. A layer of liquid plaster (height $\pm 20 \mathrm{~mm}$ ) was poured into the PVC tube so that the plaster was surrounding the claw. After the plaster dried completely, epoxy resin was poured on the claw and the plaster. The purpose of the plaster was that the epoxy resin would not be interfering with the sole and the lower parts of the horn wall (epoxy resin cannot be removed easily); the epoxy resin was used in order to confine the whole claw in a very solid block which was required to transfer forces onto the claw. Inert quartz filler was added to the resin in order to be able to dissipate the heat generated by the two-component exothermic reaction. After the epoxy resin had cured, the PVC tube and the plaster were removed.

\subsection{Roughness of concrete panels}

The roughness of the concrete floors was determined by measuring the height of the surface peaks and valleys with a high-precision laser beam (sensor ILD 1800-50 and interface optoNCDT 1800, Micro-Epsilon Messtechnik $\mathrm{GmbH}$, Ortenburg, Germany; resolution $=5 \mu \mathrm{m}$ ), mounted on an 'Automated Laser Measurement' (ALM) table developed in-house and equipped with two stepping motors controlling the motion in the $\mathrm{X}$ and $\mathrm{Y}$ direction (Franck \& De Belie, 2006); these measurements were then used to calculate $R_{a}, R_{q}$ and $R_{z}$ values according to the standard BS 1134 (1972). The $R_{a}$ value is the center-line value: through the measured profile, an average line is drawn; the roughness value is then the sum of the surface areas between the profile and the centre line over a selected reference length. Using the ALM, the $R_{a}$ value could be determined with an accuracy of $7 \mu \mathrm{m}$. The $R_{q}$ value is the root-mean-square roughness value; it is equal to the standard deviation of the roughness height distribution (BS 1134, 1972). The $R_{z}$ value is the difference between the mean of the five highest values and the mean of the five lowest values (van Beek, 2004).

For all concrete samples, three lines of intersection were taken longitudinally ( $\mathrm{Y}$ axis) and five transversely (X axis). With a reference length of $40 \mathrm{~mm}$, four consecutive profiles in longitudinal direction and two 
consecutive profiles in cross direction were measured, resulting in 22 measurements (Fig. 1). Slopes and waves due to errors of form needed to be filtered out. The roughness was measured in the centre area of the concrete panels, over which the claws were dragged. Hence, the reference point (Fig. I) was at coordinates $(x=110 \mathrm{~mm}, \quad y=420 \mathrm{~mm})$; the point $(x=0 \mathrm{~mm}$, $y=0 \mathrm{~mm}$ ) represented the lower right corner of the concrete panel. The roughness value for the whole concrete panel was the mean value of all 22 measured and corrected profiles.

The sampling rate was 43 measurements per millimetre in the $\mathrm{X}$ direction and 52 measurements per millimetre in the $\mathrm{Y}$ direction. These differences were due to the non real-time nature of the sampling.

For 'Metal' and 'Wood' finished concrete panels, more roughness measurements were available. Five panels with 'Metal' finishing were made; two of them were sandblasted ('Sand 1' and 'Sand 2') after the roughness was measured and two other 'Metal' panels were used as a basis for the synthetic floor coverings. Also two 'Wood' finished panels were made.

The roughness of the concrete panels was also approximated by uniformly spreading a fixed volume (i.e. $12280 \mathrm{~mm}^{3}$ ) of fine dry sand over the concrete surface in the shape of a circle according to the guidelines of the Belgian Research Centre for Road Building (MN. 32/69, 1969). The sand was spread to form circular patches with the 'valleys' filled to the level of the 'peaks'. The radius of the circle was measured with a pair of compasses, the surface area of the sand spot was derived and then the texture depth was calculated by dividing the sand volume through the surface area of the sand patch. Three sand patches were

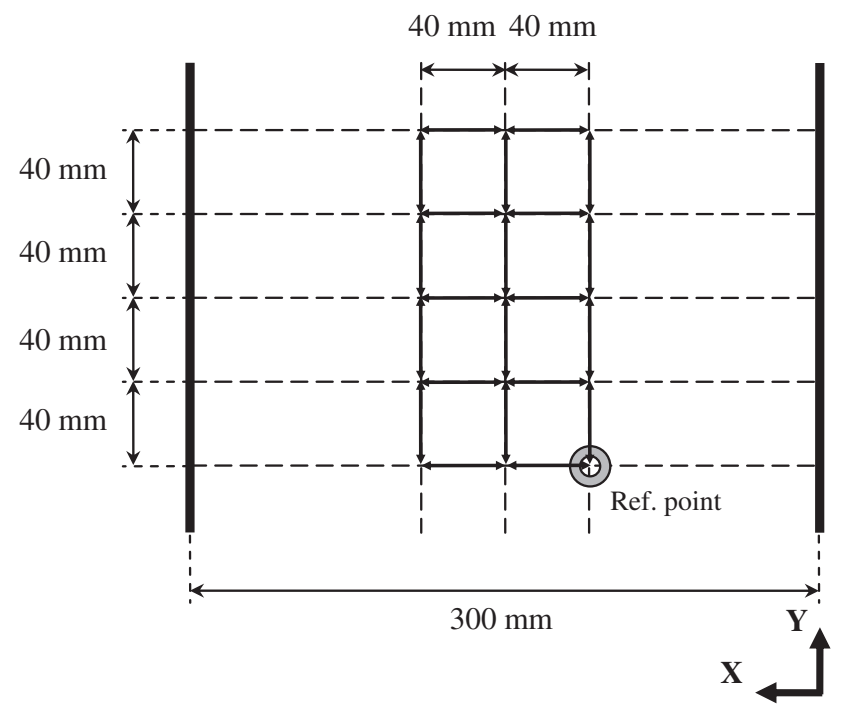

Fig. 1. Positioning of the profiles on the concrete floor samples created on one panel. The texture depth is a measure of the roughness of the floor surface: the deeper the grooves are, the more sand disappears in the grooves and the smaller is the surface of the sand patch.

The roughness of the mattress and the mat was not determined since the roughness of a soft floor does not pose any problems for the animal.

\subsection{Coefficients of friction}

The coefficient of friction $\mu$ is defined by the following equation:

$$
\mu=\frac{F_{T}}{F_{N}}
$$

where $F_{T}$ is the horizontal tensile force offering resistance to propulsion in $\mathrm{N}$; and $F_{N}$ the normal force or load in $\mathrm{N}$.

The static and the dynamic coefficients of friction ( $\mu_{\text {stat }}$ and $\mu_{d y n}$, respectively) were determined by using the 'drag method' (Nilsson, 1988). A similar device as the one described by Nilsson (1988), was used. The test rig consisted of a rigid steel frame which needed to support the concrete panels, the bovine claws and the normal loads exerted on the claws. The claws were dragged using a hand-operated winch. The crank was turned with as much uniform motion as possible. This test rig is illustrated with Fig. 2.

Two different normal loads were used: 515.2 and $947.4 \mathrm{~N}$. The weight of the claw model was added to these loads. The normal load was exerted on the bovine claw without transferring a torsional moment onto the claw model. This was achieved with a separate sub

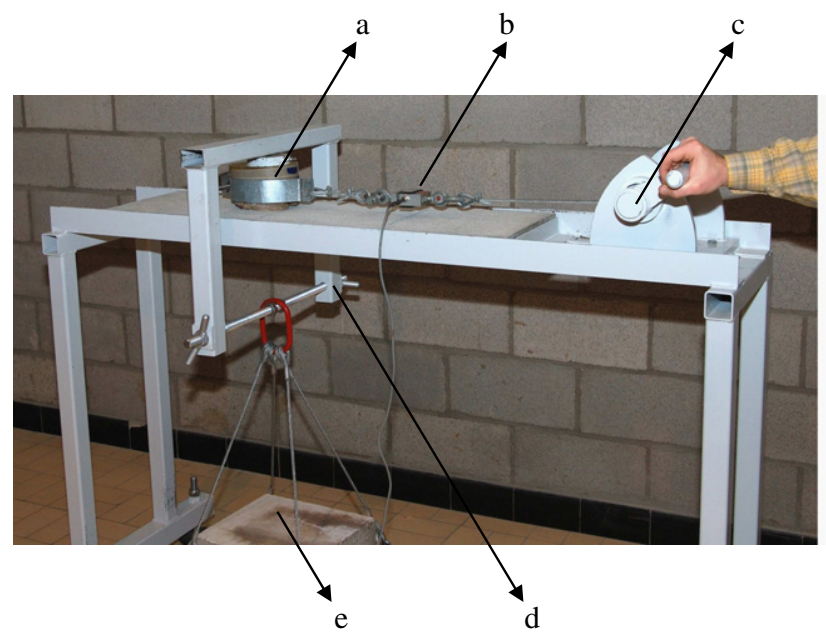

Fig. 2. Test rig used for friction measurements (a, bovine claw; $b$, load cell; $c$, winch; d, sub frame; e, load) 
frame that transferred the normal load to the claw via a 'ball-and-socket' joint (a steel plate with a cup was attached to the top surface of the claw model and the load was transferred via a pin welded on the sub frame; that pin was resting in the cup of the steel plate). The horizontal force was transferred to the claw via a steel belt that was attached around the claw model. The point of action of the horizontal force was at the bottom of the claw so that the claw model could not tilt forward. The point of action of the normal force went through the estimated centre of gravity of the claw models. A detail of the load cell and the dragging mechanism is shown in Fig. 3.

The horizontal tensile force was recorded by means of a load cell with a maximum range of $2 \mathrm{kN}$ (Sensy Model 2712, Sensors and Synergy SA, Jumet, Belgium). The signal produced by this load cell was transferred to a digital strain meter (HBM Digitaler Dehnungsmesser DMD20A, Hottinger Baldwin Messtechnik, Darmstadt, Germany) which was, in turn, attached to a scanner (System 5000, Model 5100B, Vishay Micro-Measurements, Raleigh, USA; sampling rate $=10 \mathrm{~Hz}$ ). The measurements were captured from the scanner with a personal computer running a dedicated software.

All claws were dragged over a distance of $300 \mathrm{~mm}$. Different floor samples were subsequently laid on the test rig, in a random order. All claws were tested with two loads $(515.2$ and $947.4 \mathrm{~N})$ consecutively, but the order was switched; the claws themselves were tested in a random order; they were taken out of the freezer one night before testing. The time between the application of the normal force and the drag test was about $30 \mathrm{~s}$ in order not to enable the claw to deform or to relax under the normal load.

To determine whether only one or two test runs per configuration (i.e. combination of claw, load and flooring type) were necessary, a pilot test was conducted

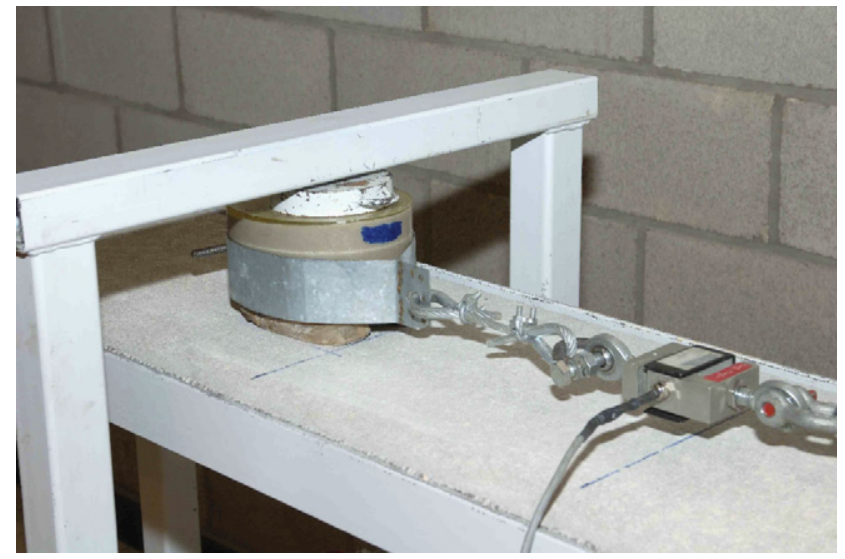

Fig. 3. Detail of claw model on concrete panel, load cell, dragging mechanism and sub frame to transfer normal load with two claws on three very distinct flooring types ('Metal', 'Sand 2' and 'Mattress N'), subjected to the two loads. This test showed no significant differences (probability $\alpha=0.05$ ) between the static and the dynamic coefficients of friction of the two runs after which it was decided to perform all other measurements with one run only. The results of the pilot test became a part of the total amount of all measurements performed.

Also tests in wet conditions were conducted: the claw soles were immersed during one night in water (depth: $20 \mathrm{~mm}$ ) and the flooring samples were made wet with a layer of water prior to testing. All claws were tested in wet conditions, but only on three distinct flooring types ('Metal', 'Sand 2' and 'Mattress N'); the most distinct flooring types were chosen after the results of the measurements in dry conditions were analysed.

Immediately after a claw was tested, the claw was frozen again.

A typical diagram indicating the fluctuation of the tensile force is shown in Fig. 4 (normal load 515.2 N). The initial peak shows the high initial force that was required to propel the claw; this force resulted in the static coefficient of friction. The dynamic coefficient of friction was determined using the mean tension force over the whole test run.

In total 350 measurements were made: 236 in dry conditions and 114 in wet conditions. Additionally a repetition test with 24 measurements was performed. The purpose of the repetition test was to check whether any degradation of the claw soles occurred during the testing; this test was performed after the test in dry conditions but before the test in wet conditions. The results of this test did not further contribute to calculation of the coefficients of friction. The repetition test had exactly the same setup as the pilot test: the same

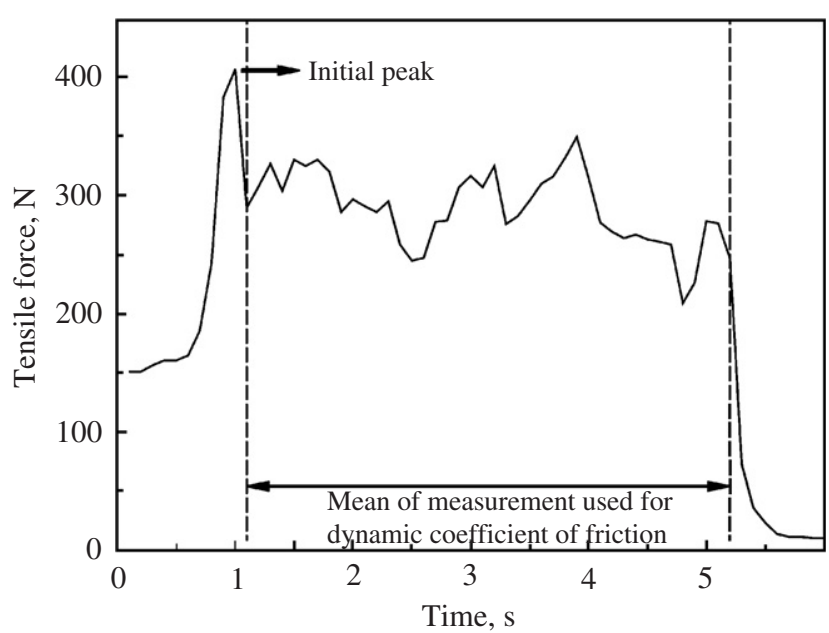

Fig. 4. Typical tensile force diagram for a test run; the initial peak can easily be observed (normal load $=515 \cdot 2 \mathrm{~N}$ ) 
claws were tested on the same floor types, with two loads and two runs per configuration. The measurements of the pilot test were compared with the results obtained from the repetition test (same amount of measurements). The pilot test and repetition test were performed in dry conditions only.

\subsection{Skid-resistance}

The slip or skid-resistance was tested with the skidresistance tester (SRT) pendulum, an apparatus very well known in road building. The SRT measurements correlate with the performance of a vehicle with patterned tyres braking with locked wheels on a wet road (Road Note No. 27, 1960). This device consisted of a friction foot (in rubber) connected to a pendulum where the foot is adjusted to sweep a path across the floor surface and the loss of energy by the pendulum is a measure of the sliding (=dynamic) friction. Concrete panels and synthetic floor coverings were tested; before they were tested, the surface was made wet. This test was performed as described in Road Note No. 27 (1960). All SRT measurements were performed by an experienced technician since experience with the SRT pendulum is mandatory for the reliability of the results.

The values obtained from the SRT pendulum were compared with roughness values and the friction measurements. The higher the pendulum swings, the less is the energy consumed due to friction between surface and rubber foot, and the SRT value is lower (the SRT pendulum first reaches the highest values on the scale; the lower values are higher on the scale). It was assumed that more rough floors cause higher friction (better skid-resistance) hence higher SRT values.

Abrasiveness was not tested since no material loss after the friction tests was measured.

\subsection{Statistical analyses}

The statistical analyses were carried out with the software package SPSS 12.0 for MS-Windows (SPSS Inc., Chicago, IL, USA). Two types of ANOVA were performed for one dependent variable: a one-way ANOVA was applied to test only one factor at a time and a univariate general linear model (GLM) was used to test the effects of more than one factor (and their interactions) at a time. Significance levels were always kept at $\alpha=0 \cdot 05$. One-way ANOVA were performed in order to assess the effects of every single variable ('Floor type', 'Claw', 'Load', and 'Limb') on the coefficients of friction. A univariate GLM was performed in order to assess the effects of all variables together on the coefficients of friction; all variables were taken as fixed factors. Appropriate post-hoc (e.g. Student-NewmanKeuls) tests were carried out in order to identify groups that are not significantly different. Also $t$-tests were performed when two series of data had to be compared with each other.

\section{Results}

\subsection{Roughness of concrete panels}

The results of the roughness measurements can be summarised with Fig. 5.

An ANOVA $(\alpha=0.05)$ proved that the surface finishing method resulted in significantly different roughness values $R_{x}$. But the Tamhane post-hoc test (for generic roughness values $R_{x}$ equal variances were not assumed) showed that there was no significant difference between the finishing methods 'Wood' and 'Sand 1' on one hand and 'Brush' and 'Sand 1' on the other hand. The 'Wood' and 'Brush' finishing methods could not be distinguished from each other with the $R_{z}$ roughness value. Figure 5 indicates the surface finishing methods that did not differ significantly: this is the case if the $95 \%$ confidence intervals for the mean values do overlap. These graphs also show that the 'Metal' and 'Sand 2' surface finishing were very distinct from each other. No significant differences between roughness values measured on $\mathrm{X}$ and $\mathrm{Y}$ oriented profiles were found.

The sand-patch method that was used for approximating the roughness of the concrete panels resulted in the following texture depths: $0.19 \mathrm{~mm}$ for 'Metal', $0.35 \mathrm{~mm}$ for 'Wood', $0.39 \mathrm{~mm}$ for 'Brush', $0.33 \mathrm{~mm}$ for 'Sand 1', and $0.59 \mathrm{~mm}$ for 'Sand 2' finished surfaces. Again these measurements showed the lowest value for the 'Metal' finishing method and the largest value for the 'Sand 2' finishing method. The values for 'Wood', 'Brush' and 'Sand 1' did not show large differences. The two-tailed Pearson correlation $\rho(\alpha=0.01)$ between the roughness values and the texture depth was considerable since it varied between 0.696 (in the case of $R_{a}$ ) and 0.790 (in the case of $R_{z}$ ).

\subsection{Coefficients of friction}

The pilot test indicated that two test runs per configuration were not necessary since a $t$-test did not show any significant difference $(\alpha=0.05)$ between the two test runs.

When the results of the pilot test were compared with the results of the repetition test, significant differences 

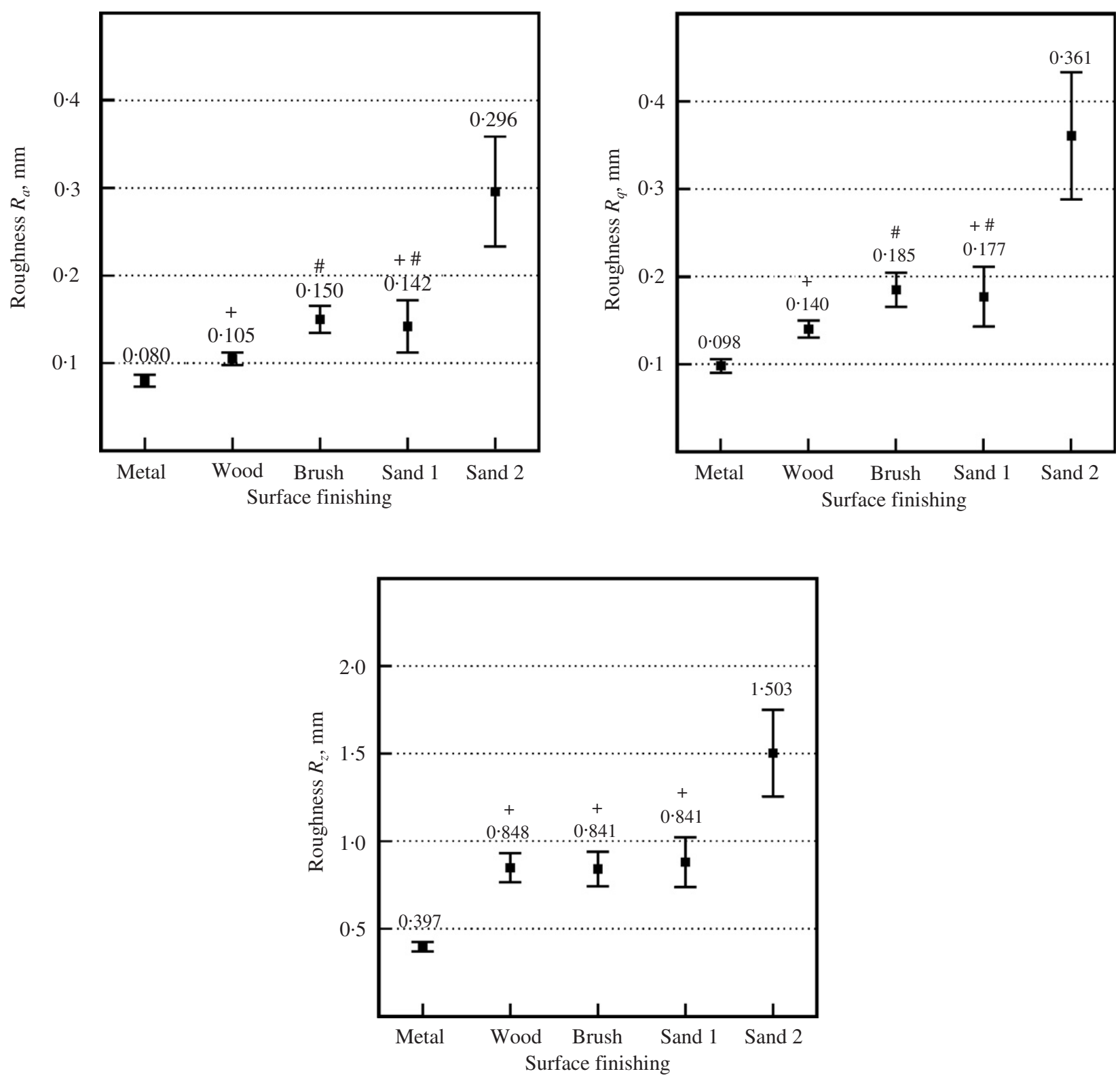

Fig. 5. Roughness values of concrete panels with different finishing methods (error bars: 95\% confidence interval for mean values); the \# and + symbols identify surfaces for which the mean coefficients are not significantly different

were found. Only one (i.e. claw 8) of the two claws was responsible for these differences.

\subsubsection{Measurements in dry conditions}

All measurements were subjected to the Kolmogorov-Smirnov test in order to test whether the measurements of the coefficient of friction followed a normal distribution. This was the case, so the ANOVA could be performed.

The results of the measurements of the coefficients of friction are summarised in Table 1.
An ANOVA showed that the variable 'Floor type' had a significant effect on the static and the dynamic coefficients of friction. When the measurements of the different flooring types were studied with the Tamhane post-hoc test, it became clear that the significant differences could be explained mainly by the measurements on three particular flooring types: concrete 'Metal', 'Mattress N' and 'Mat P' (to a lesser degree) floors resulted in different friction when compared with the other floor types. The influence of the 'Mat P' was higher on the static coefficient of friction than on the 
Table 1

Static and dynamic coefficients of friction $\left(\mu_{\text {stat }}\right.$ and $\left.\mu_{\text {dyn }}\right)$ for different floor types in dry conditions

\begin{tabular}{|c|c|c|c|c|c|}
\hline \multirow[t]{2}{*}{ Floor type } & \multirow{2}{*}{$\begin{array}{c}\text { Number of } \\
\text { samples } \\
(N)\end{array}$} & \multicolumn{2}{|c|}{$\mu_{\text {stat }}$} & \multicolumn{2}{|c|}{$\mu_{d y n}$} \\
\hline & & Mean & $S D$ & Mean & $S D$ \\
\hline Concrete 'Metal' & 38 & 0.62 & $0 \cdot 11$ & 0.58 & 0.09 \\
\hline Concrete 'Wood' & 32 & 0.71 & $0 \cdot 12$ & 0.65 & 0.07 \\
\hline Concrete 'Brush' & 32 & 0.74 & 0.09 & 0.64 & 0.06 \\
\hline Concrete 'Sand 1' & 32 & 0.79 & 0.09 & 0.68 & 0.09 \\
\hline Concrete 'Sand 2' & 36 & 0.77 & $0 \cdot 14$ & 0.69 & 0.08 \\
\hline 'Mattress N' & 38 & 0.60 & 0.07 & 0.47 & 0.05 \\
\hline 'Mat P' & 28 & $0 \cdot 70$ & 0.09 & $0 \cdot 65$ & $0 \cdot 12$ \\
\hline
\end{tabular}

SD, standard deviation.

dynamic coefficient of friction. No significant differences were found between the 'Wood', 'Brush', 'Sand 1' and 'Sand 2' concrete floor finishing methods. This means that these concrete floors resulted in the same amount of friction. There was no significant difference between the static coefficient of friction on the 'Metal' concrete floor and the 'Mattress N', but there was a significant difference in case of the dynamic coefficient of friction.

Also the variables 'Claw' (i.e. the animal) and the fore or hind 'Limb' had a significant effect on the coefficients of friction. The fore claws were found to result in significantly higher coefficients of friction than the hind claws (Fig. 6). The variable 'Load' did not cause any significant effect on the values of the coefficients of friction, but the influence of the load on the dynamic coefficient of friction $(P=0.051)$ was about 4 times larger than its influence on the static coefficient of friction. The horizontal tension force increased proportionally with the normal load on the claw.

A univariate ANOVA (general linear model) showed that the effect of the variable 'Floor type' was 2.5 (static coefficient of friction) to 6.4 (dynamic coefficient of friction) times higher than the effect of the variable 'Claw'.

The two-tailed Pearson correlations $\rho(\alpha=0.01)$ were calculated between the roughness values and the coefficients of friction. Positive and low but significant correlations were found between the static and the dynamic coefficients of friction and the $R_{a}, R_{q}$ and $R_{z}$ values, and the texture depth. These results are summarised in Table 2.

The correlation $(\alpha=0.01)$ between the static and the dynamic coefficients of friction was 0.829 .

\subsubsection{Measurements in wet conditions}

Fewer results are available since the tests in wet conditions were only performed on three types of flooring. The Kolmogorov-Smirnov test showed that only the measurements for the dynamic coefficient of friction were following a normal distribution. However, the same statistical tests (ANOVA, GLM, $t$-test) were performed on both the measurements of the static and the dynamic coefficients of friction.

The results of the measurements of the coefficients of friction in wet conditions are summarised in Table 3.

The results of the coefficients of friction measured in wet conditions were different from the results obtained in dry conditions. Analyses of variance showed that only the variable 'Floor type' had a significant effect on the coefficients of friction. The variables 'Load', 'Claw' and 'Limb' had no significant effect. The Tamhane post-hoc test showed that all three flooring types resulted in different static coefficients of friction. The same test indicated that the dynamic coefficient of friction measured on the 'Sand 2' concrete floor and the 'Mattress N' could not be distinguished from each other.

A univariate ANOVA (general linear model) showed that the effect of the variable 'Floor type' was $30 \cdot 3$ (dynamic coefficient of friction) to 58.8 (static coefficient of friction) times higher than the effect of the 'Claw'.

Positive and significant $(\alpha=0.01)$ two-tailed Pearson correlations $\rho$ were found between the static and the dynamic coefficients of friction on one hand and the $R_{a}$, $R_{q}$ and $R_{z}$ values, and the texture depth on the other hand. The correlations between the static and the dynamic coefficients of friction and the $R_{a}, R_{q}$ and $R_{z}$ values were not determined since only two roughness measurements were available (the roughness of 'Mattress N' was not measured). The correlation $(\alpha=0 \cdot 01)$ between the static and the dynamic coefficients of friction was found to be 0.873 .

\subsubsection{Comparison between dry and wet conditions}

When the static coefficients of friction in dry and wet conditions were compared by means of a $t$-test, significant differences were found. The same statement applied to the dynamic coefficients of friction. A twotailed Pearson positive and significant $(\alpha=0.01)$ correlation was found between the static coefficients of friction in dry and wet conditions $(\rho=0 \cdot 314)$, but this was not the case of the dynamic coefficients of friction. The static and the dynamic coefficients of friction in wet conditions were found to be consistently larger than the same coefficients in dry conditions. Only the dynamic coefficient of friction on a 'Metal' finished concrete floor was higher in dry conditions than in wet conditions.

\subsection{Skid-resistance}

The SRT values, measured on different floor types, are presented in Table 4 . 

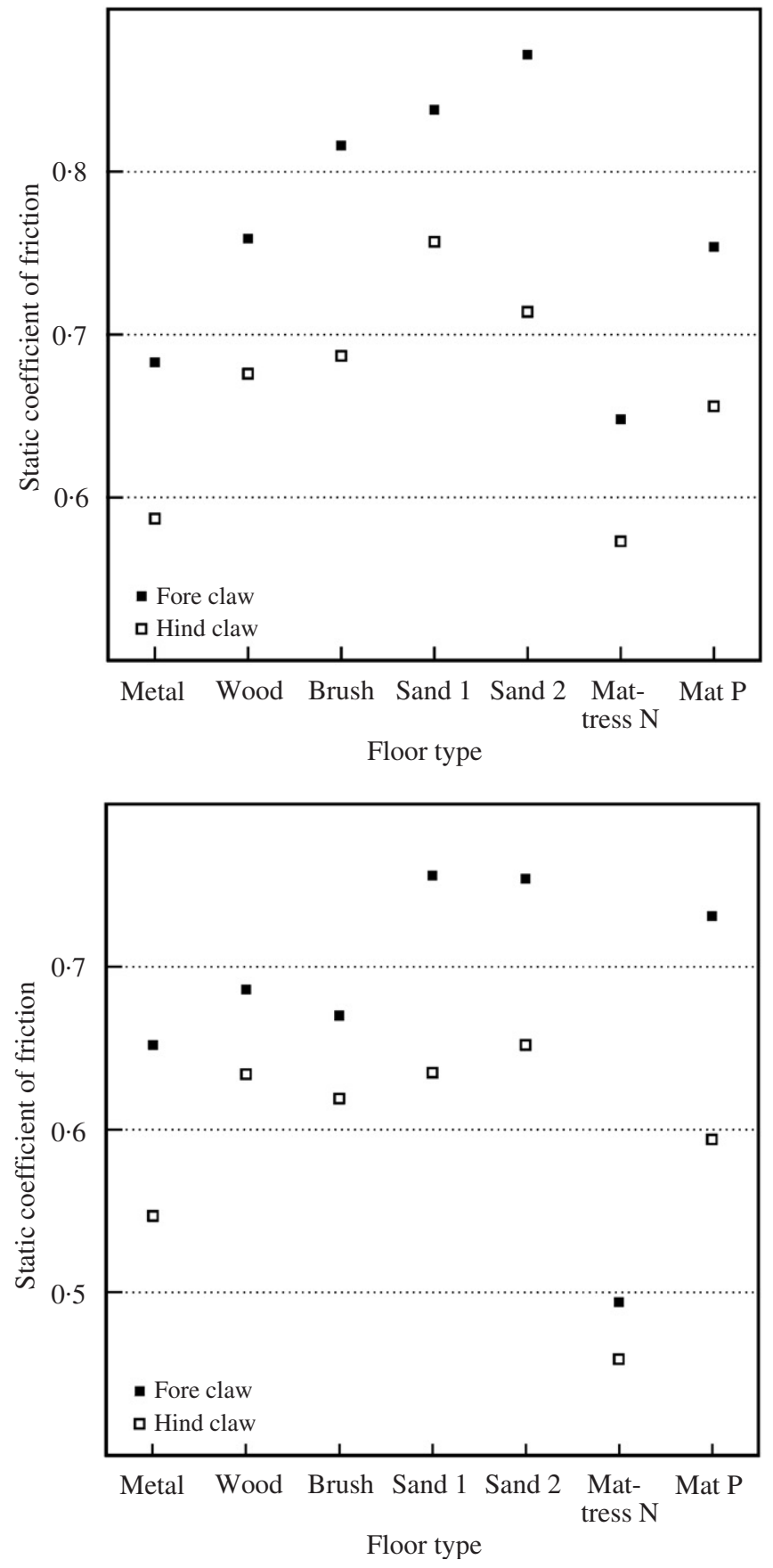

Fig. 6. Profile plots for the static and dynamic coefficient of friction in dry circumstances, indicating the difference between fore and hind claws

Analysis of variance showed significant differences between SRT values for the variable 'Floor type'. However, the Tamhane post-hoc test indicated that the floor types 'Wood', 'Sand 2' and 'Mat P' could not be distinguished from each other. The SRT value for the 'Metal' finished concrete floor is obviously very low and the SRT value for the 'Mattress N' is higher than the other SRT values. It was observed that the SRT values for the 'Mat P' were continually increasing as the test went on. This observation is consistent with the larger standard deviation.

Significant and positive two-tailed Pearson correlations $(\alpha=0.01)$ were found between the SRT values and the $R_{x}$ values, but there was no correlation between the SRT values and the texture depth (Table 5). 
Table 2

Two-tailed Pearson correlations between static and dynamic coefficients of friction $\left(\mu_{\text {stat }}\right.$ and $\left.\mu_{d y n}\right)$ and roughness values in dry conditions (probability $\alpha=0 \cdot 01$ )

\begin{tabular}{lcccc}
\hline Correlation $(\rho)$ & $R_{a}, m m$ & $R_{q}, m m$ & $R_{z}, m m$ & $T D, m m$ \\
\hline$\mu_{\text {stat }}$ & 0.309 & 0.316 & 0.367 & 0.345 \\
$\mu_{\text {dyn }}$ & 0.324 & 0.334 & 0.393 & 0.365 \\
\hline
\end{tabular}

TD, texture depth.

$R_{a}$, centre-line roughness.

$R_{q}$, root-mean-square roughness.

$R_{z}$, peak-to-valley height.

Table 3

Static and dynamic coefficients of friction $\left(\mu_{\text {stat }}\right.$ and $\left.\mu_{d y n}\right)$ for different floor types in wet conditions

\begin{tabular}{|c|c|c|c|c|c|}
\hline \multirow[t]{2}{*}{ Floor type } & \multirow{2}{*}{$\begin{array}{c}\text { Number of } \\
\text { samples } \\
(N)\end{array}$} & \multicolumn{2}{|c|}{$\mu_{\text {stat }}$} & \multicolumn{2}{|c|}{$\mu_{d y n}$} \\
\hline & & Mean & $S D$ & Mean & $S D$ \\
\hline Concrete 'Metal' & 38 & 0.65 & 0.04 & 0.56 & 0.03 \\
\hline Concrete 'Sand 2' & 38 & 0.80 & $0 \cdot 15$ & 0.69 & $0 \cdot 10$ \\
\hline 'Mattress N' & 38 & 0.71 & 0.04 & 0.66 & 0.03 \\
\hline
\end{tabular}

$\mathrm{SD}$, standard deviation.

Table 4

SRT values for different floor types

\begin{tabular}{lccccc}
\hline Floor type & $\begin{array}{c}\text { Number of } \\
\text { samples } \\
(N)\end{array}$ & \multicolumn{4}{c}{ SRT value } \\
\cline { 3 - 6 } & & Mean & SD & Min & Max \\
\hline Concrete 'Metal' & 20 & $20 \cdot 2$ & $1 \cdot 0$ & 18 & 22 \\
Concrete 'Wood' & 20 & 32.7 & $2 \cdot 4$ & 30 & 36 \\
Concrete 'Brush' & 20 & 37.7 & $1 \cdot 8$ & 35 & 42 \\
Concrete 'Sand 1' & 20 & $40 \cdot 2$ & $2 \cdot 0$ & 36 & 45 \\
Concrete 'Sand 2' & 20 & $32 \cdot 0$ & $2 \cdot 3$ & 30 & 36 \\
'Mattress N' & 20 & $49 \cdot 6$ & $1 \cdot 3$ & 47 & 52 \\
'Mat P' & 20 & 34.5 & $3 \cdot 5$ & 30 & 40 \\
\hline
\end{tabular}

$\mathrm{SD}$, standard deviation.

SRT, skid-resistance tester.

Min, minimum.

Max, maximum.

In dry conditions no correlation between the static coefficient of friction and the SRT values was found, but there was a significant and negative two-tailed Pearson correlation $(\alpha=0.01)$ between the dynamic coefficient of friction and the SRT values $(\rho=-0 \cdot 265)$. This negative correlation was probably due to the results of the 'Mattress N': this flooring type yields the highest SRT value but the lowest coefficients of friction. When the results of the 'Mattress N' and the 'Mat P' were removed from the data set, significant and positive two-
Table 5

Two-tailed Pearson correlations between the skid-resistance tester (SRT) values and the roughness values

\begin{tabular}{lccc}
\hline Correlation $(\rho)$ & $R_{a}, \mathrm{~mm}$ & $R_{q}, \mathrm{~mm}$ & $R_{z}, \mathrm{~mm}$ \\
\hline SRT & 0.264 & 0.281 & 0.427 \\
\hline
\end{tabular}

SRT, skid-resistance tester.

$R_{a}$, centre-line roughness.

$R_{q}$, root-mean-square roughness.

$R_{z}$, peak-to-valley height.

tailed Pearson correlations $(\alpha=0.01)$ were found between the static coefficient of friction and the SRT values $(\rho=0.431)$ on one hand and the dynamic coefficient of friction and the SRT values $(\rho=0.359)$ on the other hand.

In wet conditions no correlation between the static coefficient of friction and the SRT values was found. But there was a significant and positive correlation $(\alpha=0.01)$ between the dynamic coefficient of friction and the SRT values $(\rho=0.439)$. In wet conditions the coefficients of friction measured on the 'Mattress N' were more than proportionally larger than the coefficients of friction measured in dry conditions.

\section{Discussion}

\subsection{Roughness measurements}

The ratio of the variables $R_{q} / R_{a}$ was equal to 1.25 , which is perfectly in accordance with the value of 1.25 found in literature (van Beek, 2004). This means that the roughness values were according to a normal distribution. The ratio $R_{z} / R_{a}$ was equal to $6 \cdot 0$. In literature (van Beek, 2004) values between 4 and 7 are given for this ratio.

The high correlation between the $R_{x}$ values and the texture depth proves that the sand-patch method is a good and fast way to assess the floor roughness. According Road Note No. 27 (1960), the 'Metal' finished concrete floor can be considered as smooth or 'fine textured' (texture depth $\leqslant 0.254 \mathrm{~mm}$ ), the 'Wood', 'Brush' and 'Sand 1' finishing methods are 'medium textured' $(0.254 \mathrm{~mm}<$ texture depth $<0.508 \mathrm{~mm})$ and the 'Sand 2' finishing method is categorised as rough or 'open textured' (texture depth $\geqslant 0.508 \mathrm{~mm}$ ).

In the scope of a Master's thesis (Gillis, 2005) the sand-patch method was used in order to assess the roughness of stable floors of five cattle farms. For all these farms the percentage of claw diseases was also registered. The texture depth ranged between 0.29 and $0 \cdot 65$, which indicates that the range of roughness values studied in the current paper is consistent with in situ 
values. However, no significant correlation between claw diseases and texture depth was found.

Surface roughness of concrete floors was previously addressed in literature. Braam and Swierstra (1999) already described the surface roughness of differently finished concrete floors. Two finishing methods can be compared with finishing methods described in this study: finishing with a plastic float trowel ('Metal') and brushed with a broom ('Brush'). The ranges for the $R_{a}$ values for a surface finished with a plastic float trowel $(0.080-0.145 \mathrm{~mm})$ and the brushed surface $(0.090-0.160 \mathrm{~mm})$ are perfectly comparable with the results of this study (ranges: 0.018-0.193 and $0 \cdot 068-0.213 \mathrm{~mm}$, respectively).

The obtained results for surface roughness are different compared to measurements on the same panel types in De Belie and Rombaut (2003): in the current research the roughness values are consistently lower (except for 'Metal' finished), they have less variation for 'Sand 1' and are significantly higher for 'Sand 2' when compared to the other surface finishing methods. The differences are probably due to the improvements made to the ALM, allowing more precise measurement through the introduction of stepping motors (fixed amount of samples per mm). Also other regions on the concrete samples might have been measured and the measurements in De Belie and Rombaut (2003) were performed with a reference length of $50 \mathrm{~mm}(40 \mathrm{~mm}$ in the current research).

Although no roughness values are available for comparison, Phillips and Morris (2001) described the frictional and abrasive characteristics of four different surfaces (concrete covered with epoxy resin, with and without bauxite aggregates of different sizes). The floor types with the smallest aggregates $(0.5 \mathrm{~mm})$ could be compared with the 'Wood' finished concrete floor of the current study if the assumption is made that one-fifth of the mean diameters of the bauxite aggregates are compared with the $R_{a}$ values. The floor with the $0.5 \mathrm{~mm}$ aggregates seemed to be the most suitable for cows to walk comfortably (cows were taking long strides) with little risk of slip. More rough floors (aggregates 1.2 and $2.5 \mathrm{~mm}$ ) yielded higher abrasion rates which could result in sole bruising (Phillips \& Morris, 2001).

A distinction between micro-roughness and macroroughness has to be made. The former covers all features measuring $\leqslant 0.5 \mathrm{~mm}$ in horizontal direction and providing a safe frictional connection between claw and surface. In concrete, micro-roughness is a function of the surface roughness of both the aggregates and the surface mortar. Macro-roughness covers features greater than $0.5 \mathrm{~mm}$ and plays a role in a safe frictional connection between claw and surface in case of excessive soiling (Richter, 2002). In the current study (except for the 'Sand 2' finished floor) the micro-roughness was measured. The 'Sand 2' finished floor samples have high $R_{x}$ values, but in this case these values point at a large macro-roughness, while micro-roughness of the round aggregates making contact with the claws is low. Therefore, the $\mu$ values are similar or even lower than that of the 'Sand 1' finished floor.

\subsection{Coefficients of friction}

\subsubsection{Values for static and dynamic coefficient of friction}

Typical tensional force versus time traces were found (Bonser et al., 2003). These diagrams showed a rapid rise in tensional force at the beginning of the test and as the test proceeded, the frictional force varied about a mean value with no consistent trend to either increase or decrease (Bonser et al., 2003). These diagrams also clearly indicate the 'stick-slip' phenomenon (van Beek, 2004). Sometimes the amplitude of the oscillations did exceed the static peak, especially when the claws were digging into the rubber substrate ('Mat P'). The same observations were described by McClinchey et al. (2004).

The sampling rate of the scanner was $10 \mathrm{~Hz}$ and this could have been too low because the actual force peak indicating the static coefficient of friction, could have been missed due to undersampling. As such the actual peak could have been underestimated. Figure 4 is an example where the initial peak indeed could have been higher in reality, but other examples (57 out of 236 measurements in dry conditions and 28 out of 114 measurements in wet conditions) exist where there is one clear initial peak. It can therefore be concluded that underestimation did not happen systematically. And if the actual static coefficient of friction is higher, then it is clearly for the benefit of the animal.

The friction tester according to the 'drag method' used in the current study was based on a design described in an earlier study; the main difference was that a real claw was used instead of a (carved and a smooth) block of polyethylene (Nilsson, 1988). Nilsson (1988) used this kind of test rig for preliminary tests only (the extended tests were performed with an apparatus that is normally used for the determination of the fatigue resistance and for measurements of wear).

Nilsson (1988) tested on two types of concrete floors: on 'steel-trowelled concrete' as a worn type and on 'floated concrete' as a new type. The latter type could be compared with the 'Metal' finished concrete used in this study. Nilsson (1988) found the dynamic coefficient of friction to be between 0.35 and 0.38 (curve interpolated at a normal load of 500 and $900 \mathrm{~N}$, respectively). These 
values are considerably lower than the values found in the current study. The differences could be explained by the fact that Nilsson (1988) did not use real claw models since the claw itself also has an influence on the coefficients of friction.

Nilsson (1988) also tested many rubber mats and mattresses. The dynamic coefficient of friction was 0.60 for a mattress with a thickness of $40 \mathrm{~mm}$ and between 0.70 and 0.77 (curve interpolated at a normal load of 500 and $900 \mathrm{~N}$, respectively) for a rubber mat. These values are a better match for the values found in the current study.

Nilsson (1988) found that the static coefficient of friction showed a larger variation than the dynamic coefficient of friction and for hard materials no significant differences were found between the coefficients of friction obtained with different normal forces. The same conclusions can be drawn from the results of the current study.

The static coefficient of friction was always larger than the dynamic coefficient of friction. This seems logical for hard concrete surfaces, but is less obvious for soft synthetic surfaces since the value of the coefficient of friction could be expected to increase with the claw's penetration in the soft flooring material (McClinchey et al., 2004). Presumably, the normal loads applied in the current study were not high enough to cause a deep penetration in the soft mattress or mat. Nilsson (1988) used normal loads up to $2460 \mathrm{~N}$ and only with that force he found significantly higher coefficients of friction on soft materials (the maximum load applied in the current study was $947.4 \mathrm{~N})$.

Bonser et al. (2003) used a similar, but more sophisticated test rig to investigate the frictional properties of dry and wet claw horn. Only small horn samples could be tested with this device. Two kinds of surfaces were used: strips of 'smooth' (particle size $=0.065 \mathrm{~mm}$ ) and 'rough' (particle size $=0.412 \mathrm{~mm}$ ) abrasive paper; the latter could be compared with the 'Metal' finished concrete (under the assumption that one-fifth of the particle size is compared with the $R_{a}$ values). Bonser et al. (2003) did not make a distinction between the static and the dynamic coefficients of friction, but calculated the mean frictional force over the test period which means that the frictional coefficients can be considered as dynamic coefficients of friction. The found coefficients of friction were 0.70 and 0.75 on smooth abrasive paper for dry and wet horn samples, respectively, and 0.86 and 0.88 on rough abrasive paper for dry and wet horn samples, respectively. These values are considerably higher than the values found in the current research. Bonser et al. (2003) did not find a significant effect of the water content on the frictional coefficients. This could be due to the small amount of tests performed ( $\mathrm{N}$ ranged between 2 and 5, depending on the case).

Bonser et al. (2003) concluded that surface roughness appears to be the main driver in mediating friction. This statement seems exaggerated considering the rather low correlations found in this study between the static and the dynamic coefficients of friction and the roughness values.

The dynamic coefficient of friction is more relevant from a biomechanical point of view to the risk of slips and falls (Phillips \& Morris, 2000).

Phillips and Morris (2000) investigated the locomotion of dairy cows on dry and wet concrete floors. In the same study, the profile (i.e. the depth of the undulations in the floor surface that had been caused by tamping during construction) of the floor surfaces and the frictional coefficients was measured. The roughness was not measured, but the concrete surface was four years old and was tamped using a wooden board. The coefficients of static and dynamic friction were measured with a weighted platform (load $=1471.5 \mathrm{~N})$ with four bovine claws beneath it to simulate a cow moving over the floor. The static coefficients of friction were 0.51 and 0.57 , respectively for dry and wetted concrete; the dynamic coefficients of friction were 0.43 and 0.51 , respectively for dry and wetted concrete. These values are somewhat lower than the ones found in this study. The dynamic coefficients of friction were lower than the static coefficients of friction, the same situation as encountered in the current study.

Phillips and Morris (2001) measured the static and the dynamic coefficients of friction of floors covered with epoxy resin containing bauxite aggregates when assessing the locomotive behaviour of cows. The coefficients of static and dynamic friction were measured with the same weighted platform as used in their previous study (Phillips \& Morris, 2000). The static and the dynamic coefficients of friction were 0.42 and 0.61 , respectively, for aggregates with a diameter of $0.5 \mathrm{~mm}$. The value for the static coefficient of friction is considerably lower than the value found for the 'Wood' finished floor $\left(\mu_{\text {stat }}=0.71\right)$ in the current study; this could be explained by the fact that bauxite aggregates could have been rather round and that the tensile force required to drag the claws was therefore lower (the aggregates function as a kind of 'bearing'). The dynamic coefficient of friction is in accordance with the value found for the 'Wood' finished floor $\left(\mu_{d y n}=0.65\right)$ in the current study. The dynamic coefficient of friction was higher than the static coefficient of friction and this was unexpected; this may have been due to the braking forces produced when the claws were in contact with the large aggregates (Phillips \& Morris, 2001). 
For cattle, it is likely that the dynamic friction most accurately reflects the risk of slip at the start of the supporting limb phase, when the claw is gaining contact with the floor. Static friction may most accurately represent the risk of slip before lifting the limb, since the claw is static at this time (Phillips \& Morris, 2001). Phillips and Morris (2001) concluded that the optimum coefficient of friction for cattle floors is between 0.4 and 0.5 because on low friction floors $(\mu<0.4)$ cows walk quickly with frequent, short steps. As the coefficient of friction increases to $0 \cdot 5$, step length increases and the number of steps decreases to maintain speed at increased friction. The coefficients of friction found in the current study are all higher. When the friction increases over 0.5 , the hanging limb phase may be increased at the expense of the supporting limb phase, so the cows will try to reduce contact with the floor in order to compensate for the increased friction (Phillips \& Morris, 2001).

The values for the static and the dynamic coefficients of friction can also be compared with friction measurements between horses' hooves and concrete floors. McClinchey et al. (2004) determined the static and the dynamic coefficients of friction between whole horses' hooves and an unpatterned concrete surface to be 0.887 and 0.710 , respectively. For the same test on patterned rubber (which can be compared with 'Mat $\mathrm{P}$ ' in the current study), McClinchey et al. (2004) found values of 1.024 and 0.821 , respectively, for the static and the dynamic coefficients of friction. The test method was similar to the test method used in the current study, with the only exceptions that four hooves instead of one claw were tested and that the hooves remained stationary while the substrate was pulled away. The friction values found by McClinchey et al. (2004) were higher than the values found in the current study. However, the dynamic coefficient of friction was also lower than the static coefficient of friction. The differences may have several causes: variations in material properties between equine and bovine claw horn, variations in volume and toe angle of the claws and hooves, and the variations in roughness of the substrates used in the two studies. McClinchey et al. (2004) also found no significant effect of the load on the coefficients of friction.

In a Danish study (Pedersen, 2005) on the use of concrete floor types in pig pens, the static and the dynamic coefficients of friction of a polyurethane 'claw' on dry and wet concrete floors were determined. The test equipment was a four wheeled cart running on the rails of a frame; the frame itself was placed on the test surface and the 'claw' was then connected to the cart and pulled over the test surface. This test method is also a drag test, so results can be compared with of the current study. The dynamic coefficient of friction measured on a solid concrete floor (no roughness indication) was 0.47 in dry conditions and 0.50 in wet conditions; the static coefficient of friction was $21 \%$ higher than the dynamic coefficient of friction for dry conditions. The dynamic coefficient of friction measured on a concrete floor with a brushed surface was 0.73 in dry conditions and 0.77 in wet conditions; the static coefficient of friction was $38 \%$ higher. The values on the solid concrete floor are lower than the ones found in the current study and the values on the brushed concrete floor are higher. The differences in friction can be explained by the probably different surface roughness, and by the different material (polyurethane) used for the 'claw'. The values in wet conditions are also higher than the values found in dry conditions. Another similarity between the Danish study and the current study is that there was no relation between the normal load and the coefficients of friction.

\subsubsection{Coefficients of friction in dry and wet circumstances}

In the current study higher coefficients of friction were obtained on wet material than on dry material. Phillips and Morris (2000) and Pedersen (2005) found the same result. Nilsson (1988) and Bonser et al. (2003) found no statistical differences between the coefficient of friction for dry and wet concrete surfaces and dry and wet horn samples, respectively, on abrasive paper. Although water is considered to be a lubricant which reduces friction, dry claws slip more easily than moistened claws, as the latter adapt themselves to the underlying surface (Nilsson, 1988). Phillips and Morris (2000) provided a more precise explanation: they presumed that the wetting of the dead claws had rehydrated the solar tissue, leading to swelling and softening of the parts in contact with the ground. This could increase friction by increasing the flexibility of the tissue and increasing the contact points between the sole and the floor. The live claw would probably be less influenced by the presence of water on concrete (Phillips \& Morris, 2000).

The much higher effect of the 'Floor type' than the 'Claw' on the coefficients of friction in wet conditions is presumably due to the layer of water between the claw and the floor sample. A rougher floor could hold a larger amount of water in the 'valleys' of the surface. The water film which causes a lubricating effect can be sustained better in rougher floors. Also moisture changes the horn properties of the bovine claw (the claws were immersed in water overnight); this could equalise the stiffness of the horn which causes the effect of the claw itself to decrease.

The correlations between the coefficients of friction in wet conditions and the roughness values are less reliable since only two panels with known roughness were taken 
into account (the roughness of the 'Mattress N' was not measured). Nevertheless the results are valuable since the two most distinct floors ('Metal' and 'Sand 2') regarding roughness were included in the test.

\subsubsection{Effect of claw conformation}

The conformation of the claw had an influence on the measured coefficients of friction since the coefficients of friction measured with the fore claws were significantly higher than the coefficients of friction measured with the hind claws. Fore claws are larger than hind claws. Newtonian principles of mechanics indicate that the coefficient of friction is independent of the surface area of the object in contact with the floor. However, Phillips et al. (1998) found that larger claws had a rougher, less uniform surface which induced a greater coefficient of friction.

The significant differences between the pilot and the repetition test indicated that degradation of the claws occurred during the test. The amount of degradation might not be the same for all claws since only one of the two claws was responsible for the differences between pilot test and repetition test. But the consecutive freezing and defrosting of the claw samples could also have affected the frictional properties (McClinchey et al., 2004). The claws were frozen between the pilot test and the main test in dry circumstances, between the tests in dry and wet circumstances and between the test in wet conditions and the repetition test. Freezing and defrosting of the claws cause them to dry (McClinchey et al., 2004) and dehydration changes the biomechanical properties of the bovine claw horn.

\subsubsection{Required coefficient of friction}

In order to be able to assess the risk of slipping in cattle housing, knowledge of the minimum required coefficient of friction is required. Van der Tol et al. (2005) determined the required (static) coefficients of friction for unrestrained locomotion of healthy dairy cows on a nonslippery floor. The maximum required coefficient of friction ranged from 0.83 (straight walking) to 0.85 (walking a curve) which occurred, respectively, at heel strike and at push off. At steady-state required coefficients of friction of 0.4 were found. The tests performed in the current study should only be compared with the values of the required coefficient of friction at steady-state i.e. not in the beginning or at the end of the stance phase. The coefficients of friction that were measured in this study were all higher than the required coefficient of friction during the steady-state stance phase.

\subsection{Skid-resistance}

Skid-resistance is dealt with in separate paragraphs since beforehand it was not known whether the SRT measurements would be a good way to either assess the roughness or to estimate the coefficients of friction.

The SRT values are all below 45, except the SRT value for the 'Mattress N'. According to Road Note No. 27 (1960), SRT values below 45 are to be considered as 'potentially slippery'.

According to NEN 2873 (1982), Leroux values (which are essentially SRT values) below 40 indicate that the floor is too slippery for humans, between 40 and 50 the floor does not provide enough skid-resistance for walking and between 50 and 60 the floor provides enough to good skid-resistance for walking. This means that only 'Mattress N' would provide acceptable results. These values are confirmed by Richter (2002).

The SRT values for the 'Mat P' increased over the 20 measurements as the test went on. This could be caused by the heating due to the friction between the rubber surfaces of the foot of the pendulum and the mat. The effect of temperature on rubber resilience exerts a perceptible influence in all skidding-resistance measurements: skidding tends to fall (SRT values increase) as temperature rises (Road Note No. 27, 1960).

The significant correlations between the SRT values and the roughness values $R_{x}$ show that the SRT method could be used to relatively compare the roughness of different floors with each other. The SRT pendulum can only be used for assessing microroughness (Richter, 2002).

More important is that the SRT measurements are positively correlated with the dynamic coefficient of friction in wet conditions. This seems logical since the SRT measurements were also performed on wet floors. The SRT pendulum can be used to assess the dynamic frictional properties of wet floors of any nature. However, the SRT pendulum can also be used for assessing the static and the dynamic frictional properties of concrete surfaces.

The SRT pendulum is widely used in the construction of roads, where driving speeds are above $50 \mathrm{~km} / \mathrm{h}$. However, this device is still applicable for the slow speeds at which cattle normally move. The critical element is the slipping speeds which have invariably been found to be above $1.5 \mathrm{~m} / \mathrm{s}$ and as high as $5 \mathrm{~m} / \mathrm{s}$ in extreme cases. The pendulum speed of $2.8 \mathrm{~m} / \mathrm{s}$ is therefore within the range of slipping speeds (Richter, 2002).

\section{Conclusion}

In the current study, the determination of the roughness of concrete floors and the influence of floor roughness on frictional properties and slip-resistance was presented. Also the frictional properties and the 
skid-resistance of two types of synthetic flooring surfaces (a mat and a mattress) were tested.

The most distinct surface roughness occurred with metal-finished and severely sandblasted concrete floors ( $R_{a}$ values equal to 0.080 and $0.296 \mathrm{~mm}$, respectively). There was no significant difference in roughness between concrete surfaces that were finished with a wooden float and those that were brushed and mildly sandblasted. The sand-patch method proved to be a valuable way to assess the roughness of concrete panels and can be performed very fast on any location.

Different floor types yield different frictional properties; these differences are mainly explained by the synthetic floor coverings since there was hardly any difference between the wood-floated, brushed, and mildly and severely sandblasted concrete finishing methods. The mattress caused the least, but still enough friction. Claws from fore limbs result in higher friction than claws from hind limbs (in dry conditions). The floor roughness and the friction are positively correlated.

The static coefficient of friction was consistently larger than the dynamic coefficient of friction.

In dry conditions the effect of the floor type is higher than the effect of the claw, hence the animal itself. In wet conditions the effect of the floor type is an order of magnitude higher when compared with the effect in dry conditions. The friction is generally higher in wet conditions than in dry conditions.

\section{Acknowledgements}

The authors would like to thank the Special Research Fund (BOF) of Ghent University for the funding of this research (Project No. 01113203 and 011B4101). The Faculty of Bioscience Engineering is thanked for their contributions and support.

The authors would like to thank the Unit Technology and Food-Agricultural Engineering which belongs to the Institute for Agricultural and Fisheries ResearchILVO of the Ministry of the Flemish Community for the SRT measurements.

The authors also thank Roy Mooney (R.J. Mooney \& Son Ltd., Dublin, Ireland) for providing the synthetic floor coverings.

\section{References}

Bonser R H C; Farrent J W; Taylor A M (2003). Assessing the frictional and abrasion-resisting properties of hooves and claws. Biosystems Engineering, 86(2), 253-256

Braam C R; Swierstra D (1999). Volatilization of ammonia from dairy housing floors with different surface character- istics. Journal of Agricultural Engineering Research, 72, $59-69$

BS 1134 (1972). British Standard Method for the Assessment of Surface Texture - part 1: Method and Instrumentation \& part 2: General Information and Guidance. British Standards Institution

Cook N B; Nordlund K V; Oetzel G R (2004). Environmental influences of claw horn lesions associated with laminitis and subacute ruminal acidosis in dairy cows. Journal of Dairy Science, 87(E. Suppl.), E36-E46

De Belie N; Rombaut E (2003). Characterisation of claw-floor contact pressures for standing cattle and the dependency on concrete roughness. Biosystems Engineering, 85(3), 339-346

De Kruif A; Opsomer G (2005). Integrated dairy health management as the basis for prevention. Flemish Veterinary Journal, 73, 44-52

Franck A; De Belie N (2006). Concrete floor - bovine claw contact pressures related to floor roughness and the deformation of the claw. Journal of Dairy Science, 89(8), 2952-2964

Gillis I (2005). Invloed van roostervloeren op de klauwgezondheid en het uitglijden bij runderen. [Effect of slatted floors on claw health and slipping of cows.] Master's Thesis, Faculty of Veterinary Medicine, Ghent University, Gent, Belgium

McClinchey H L; Thomason J J; Runciman R J (2004). Grip and slippage of the horse's hoof on solid substrates measured ex vivo. Biosystems Engineering, 89(4), 485-494

McDaniel B; Wilk J (1991). Lameness in dairy cows. In: Proceedings of the British Cattle Veterinary Association, pp 66-80

MN. 32/69 (1969). Zandvlekproef - bepaling van de gemiddelde nivelleringsdiepte der groeven van cementbetonverhardingen, werkwijze. [Sand-patch method-determination of the texture depth of the grooves of hardened concrete surfaces, guidelines.] Belgian Research Centre for Road Building, Brussels, Belgium

NEN 2873 (1982). Beproeving van steenachtige materialenStroefheidsmeter volgens Leroux en bepaling van de stroefheid van oppervlakken. [Testing of stony materials-Skidresistance apparatus according Leroux and determination of surface frictional properties.] Modified by NEN 2873:1982/ C1:1988, NEN 2873:1982/A1:1999. Dutch Standards Institution, Delft, The Netherlands

Nilsson C (1988). Floors in animal houses-Technical design with respect to the biological needs of animals in reference to the thermal, friction and abrasive characteristics and the softness of the flooring material. Report 61. Swedish University of Agricultural Sciences, Department of Farm Buildings, Division of Agricultural Building Technology, Lund, Sweden

Pedersen S (2005). Friction and shock absorption for floors in pig pens. In: Proceedings of the Fifth International Symposium on Concrete for a Sustainable AgricultureAgro-, Aqua- and Community Applications (Sánchez Espinosa E; Garcimartín M A, eds), pp 229-238, San Lorenzo de El Escorial, Spain

Phillips C J C; Coe R; Colgan M; Duffus C; Ingoldby L; Pond M; Postlethwaite S (1998). Effect of hoof characteristics on the propensity of cattle to slip. The Veterinary Record, 142, 242-245

Phillips C J C; Morris I D (2000). The locomotion of dairy cows on concrete floors that are dry, wet, or covered with a slurry of excreta. Journal of Dairy Science, 83, 1767-1772 
Phillips C J C; Morris I D (2001). The locomotion of dairy cows on floor surfaces with different frictional properties. Journal of Dairy Science, 84, 623-628

Richter T (2002). Skid proofing of concrete stable floors. In: Proceedings of the Fourth International Symposium on Concrete for a Sustainable Agriculture-Agro-, Aqua- and Community Applications (De Belie N; Sonck B, eds), pp 61-68, Gent, Belgium

Road Note No. 27 (1960). Instructions for using the portable skidresistance tester. Road Research, Department of Scientific and Industrial Research, Road Research Laboratory, London, UK

Shearer J K; van Amstel S R (2003). Managing lameness for improved cow comfort and performance. In: Proceedings of the Sixth Western Dairy Management Conference, pp 167-178, Reno, USA

Somers J G C J; Frankena K; Noordhuizen-Stassen E N; Metz J H M (2003). Prevalence of claw disorders in Dutch dairy cows exposed to several floor systems. Journal of Dairy Science, 86, 2082-2093

Somers J G C J; Schouten W G P; Frankena K; NoordhuizenStassen E N; Metz J H M (2005). Development of claw traits and claw lesions in dairy cows kept on different floor systems. Journal of Dairy Science, 88, 110-120

van Beek A (2004). Machine Lifetime Performance and Reliability. Tribos, Delft, The Netherlands

van der Tol P P J; Metz J H M; Noordhuizen-Stassen E N; Back W; Braam C R; Weijs W A (2002). The pressure distribution under the bovine claw during square standing on a flat substrate. Journal of Dairy Science, 85, 1476-1481

van der Tol P P J; Metz J H M; Noordhuizen-Stassen E N; Back W; Braam C R; Weijs W A (2005). Frictional forces required for unrestrained locomotion in dairy cattle. Journal of Dairy Science, 88, 615-624

Vermunt J J (1996). Factors affecting the growth rate of claw horn in cattle. Proceedings of the Ninth International Symposium on Disorders of the Ruminant Digit and the International Conference on Lameness in Cattle, Jeruzalem, Israël

Vermunt J; Greenough P (1996). Claw conformation of dairy heifers in two management systems. British Veterinary Journal, 152, 321-331 